Alunos indígenas da etnia xavante e professores não índios: o ensino da língua 2 em contexto de interculturalidade $\mid 215$

\title{
ALUNOS INDÍGENAS DA ETNIA XAVANTE E PROFESSORES NÃO ÍNDIOS: O ENSINO DA LÍNGUA 2 EM CONTEXTO DE INTERCULTURALIDADE
}

\author{
Marly Augusta Lopes de Magalhães ${ }^{79}$ \\ Mônica Maria dos Santos ${ }^{80}$
}

RESUMO: Este artigo é o resultado de uma pesquisa que tinha como objetivo principal verificar o processo de ensino da Língua 2 aos alunos indígenas matriculados em escolas públicas estaduais da cidade de Barra do Garças/MT. Outros objetivos foram definidos: conhecer os pontos conflitantes entre a língua materna e a Lingua 2; Identificar as principais dificuldades no ensino da Língua 2; Oferecer um curso para propiciar encontros entre professores e alunos indigenas e professores não indigenas, principalmente, para aqueles que trabalham com alunos indigenas da Etnia Xavante no dia a dia escolar. Esses alunos buscam, em espaços urbanos, a sua socialização junto à sociedade não indígena. Os autores que fundamentaram os estudos foram Bakhtin, Ferreiro, Freitas, Freitas \& Queiroz, Grupione, Laraia, Marzari, Minayo, Neves, Pimentel da Silva, Rego, Tozoni-Reis. Para a realização da pesquisava utilizou-se a metodologia qualitativa que, por meio da observação participante, possibilitou a descrição da complexidade que envolve o ensino da Língua 2, envolvendo os professores não índios e os alunos indígenas. Os resultados da pesquisa mostraram que existem conflitos entre as diferentes culturas e pouco interesse na compreensão dos processos dinâmicos vividos por diferentes grupos sociais na assimetria refletida no ensino da Lingua Portuguesa.

Palavras-chave: Alunos Indígenas. Professores não índios. Ensino. Interculturalidade.

ABSTRACT: This article is the result of a research which main objective was to verify the teaching process of Language 2 to indigenous students

\footnotetext{
79 Doutora em Ciências Linguísticas pela Universidad Central de Las Villas - Cuba. Professora Associado I da Universidade Federal de Mato Grosso-UFMT. Editora-chefe Revista Multidisciplinar Panorâmica.

${ }^{80}$ Mestre em Letras pela Universidade Federal de Rondônia-UNIR. Professora Assistente da Universidade Federal de Mato Grosso-UFMT
} 
enrolled in public state schools in Barra do Garças/MT. The other objectives were set : to acknowledge the aspects of conflict between mother tongue and the Language 2; to identify the main difficulties in teaching Language 2; to offer a course to propitiate meetings among teachers and indigenous students and non-indigenous teachers, mainly to those who work with students from Xavante Ethical group on a day-to-day school routine. These students search, in urban areas, their socialization with the non-indigenous society. The authors who founded the studies were Bakhtin, Ferreiro, Freitas, Freitas \& Queiroz, Grupione, Laraia, Marzari, Minayo, Neves, Pimentel da Silva, Rego, Tozoni-Reis. For the research accomplishment, quantitative methodology was used that, through the participant observation, allowed the description of complexibility that involves the teaching of the Language 2, involving the non-indigenous teachers and the indigenous students. The results of the research showed that there are conflicts between the different cultures and little interest in the comprehension of the dynamic processes lived by different social groups in the asymmetric reflection in the teaching of the Portuguese Language.

Keywords: Indigenous Students, Non-indigenous teachers. Teaching. Interculturality.

\section{Introdução}

Sempre que se discutem problemas relacionados a qualquer tipo de inclusão, principalmente, de alunos indígenas da Etnia Xavante, surgem algumas questões essenciais que obrigam a tomada de posicionamento e, assim, fazer algumas escolhas.

Dessa forma, a escolha deste estudo pautou-se na problemática que envolve o ensino da língua portuguesa e teve como problema de pesquisa: Como tem sido o ensino da Língua 2 nas escolas públicas de Barra do Garças que atendem alunos da Etnia Xavante?

Assim, esse estudo teve como objetivo identificar a prática de professores de língua portuguesa em ambiente intercultural, mais especificamente, no âmbito das escolas públicas estaduais de Barra do Garças/MT, principalmente as que possuem alunos indigenas matriculados nas diversas modalidades de ensino.

Para isso, iniciou-se uma formação de professores organizada em parceria com o Campus Universitário do Araguaia/Universidade Federal de Mato Grosso com o Centro de Formação dos Profissionais da 
Alunos indígenas da etnia xavante e professores não índios: o ensino da língua 2 em contexto de interculturalidade | 217 Educação Básica - CEFAPRO que atua com a formação continuada dos profissionais da educação básica. O referido curso denominado "A presença dos estudantes indigenas da Etnia Xavante no marco interacional das escolas públicas urbanas: uma estratégia de contato". Essa formação tinha como finalidade propiciar encontros entre professores, alunos indigenas e professores não indígenas, principalmente, para aqueles que trabalham com alunos indígenas da Etnia Xavante no dia a dia escolar.

Entende-se que ninguém transforma o mundo sozinho, pois para que se tenha êxito nas questões relacionadas a inclusão é imprescindivel que várias mãos e diferentes cabeças busquem um objetivo comum, pois todas as pessoas, independentes da raça, da cor, da cultura, da língua, de gêneros, necessitam de chances para aprender e, dessa forma, construir seu próprio caminho.

Em busca dessa construção, algumas decisões éticas e jurídicas que revestem esses seres, principalmente os povos indígenas devem ser observadas, a fim de que não venham ferir sua cultura, sua língua e sua identidade.

As incessantes transformações das comunidades indígenas são a marca digital deste início de século. É preciso, portanto, que a comunidade não indígena aperfeiçoe seus mecanismos de contatos com essa nova realidade, a fim de que os direitos constitucionais desses povos, em contextos urbanos, não se tornem invisiveis.

Nos últimos tempos, a sociedade caminha para uma homogeneidade em suas formas de atuação e de participação na economia, na politica, no social, no cultural, além de outras que trazem, em seu bojo, a necessidade de se ter cuidado com a exclusão de minorias ou com a perda da identidade linguística e cultural nelas depositadas. Para Vygotsky

[...] a cultura não é pensada como algo pronto, um sistema estático ao qual o indivíduo se submete, mas como uma espécie de "palco de negociações", em que seus membros estão num constante movimento de recriação e reinterpretação de informações, conceitos e significado (OLIVEIRA, 1993, p. 38 Apud REGO, T. C., 2003, p. 56).

Nessa mesma linha de pensamento, Geertz, define a cultura "[...] como um sistema ordenado de significações e símbolos em virtude dos 
quais os indivíduos definem seu mundo, expressam seus sentimentos e formulam seus juízos" (GEERTZ, 2001, p. 707).

Trata-se de um trabalho que teve como motivação dar continuidade a trajetória de investigadora, iniciada com a experiência de professora que desenvolve vários projetos de pesquisa e extensão junto aos jovens indígenas da Etnia Xavante em espaços públicos urbanos, mais especificamente, com alunos matriculados em escolas públicas estaduais urbanas, pois o que se tem vivenciado, nas últimas décadas, é a crescente migração das aldeias para as cidades em busca da própria sobrevivência.

\section{O Caminho da pesquisa}

Para realização do estudo buscou-se os fundamentos da pesquisa qualitativa, pois se considera que os fenômenos humanos e sociais nem sempre podem ser quantificáveis, uma vez que "[...] trata-se de um universo de significados, motivos, aspirações, crenças, valores e atitudes, o que corresponde a um espaço mais profundo das relações dos processos e dos fenômenos que não podem ser reduzidos à operacionalização de variáveis". (MINAYO, 2002, p. 17). Assim, "[...] a pesquisa qualitativa defende a ideia de que, na produção de conhecimentos sobre os fenômenos humanos e sociais, nos interessa mais compreender e interpretar seus conteúdos do que descrevê-los, explicá-los" (TOZONIREIS, 2009, p. 10). Nessa perspectiva,

[...] a pesquisa qualitativa dá condições para entender o indizivel, aquilo que está além das aparências, uma vez que sua intenção se volta para as dimensões da realidade que se manifestam, às vezes, de forma incipiente nas práticas, nos hábitos, nas crenças, nos valores, na linguagem, na cultura, entre outras dimensões presentes nas pessoas envolvidas no estudo (MARZARI, 2016, p. 27).

Para o levantamento dos dados utilizou-se da pesquisa de campo e da observação participante para que se pudesse conhecer o que era proposto aos alunos indígenas sobre o ensino da língua portuguesa em eventos comunicativos de sala de aula urbanas, ou seja, fora de seu habitat natural, as aldeias.

Os dados foram coletados a partir de observação de alunos indígenas da Etnia Xavante matriculados nas escolas públicas estaduais 
Alunos indígenas da etnia xavante e professores não índios: o ensino da língua 2 em contexto de interculturalidade | 219 urbanas, mas especificamente, àquelas com maior concentração de matrículas.

O estudo pautou-se, sobretudo, nos aspectos sociointeracionais referentes ao ensino da língua 2 (portuguesa), em ambiente intercultural, mais especificamente, para alunos indígenas da Etnia Xavante, no âmbito das escolas públicas estaduais urbanas na cidade de Barra do Garças/MT.

Para o desdobramento da pesquisa, elegeu-se, inicialmente, a discussão sobre algumas das propostas funcionalista e intercultural, o que provocou a leitura dos trabalhos de Bakhtin, (2002), Ferreiro (1985), Freitas (1994), Freitas \& Queiroz (2012), Grupione (1995), Laraia (2009), Marzari (2016), Minayo (2002), Neves (2002, 2006, 2007, 2010, Pimentel da Silva (2010), Rego (2013), Tozoni-Reis (2009).

Daí o trabalho ter como foco a verificação de como se dá o aprimoramento das competências linguísticas e comunicativas dos alunos indigenas, que vivem experiências de ensino de língua portuguesa, em contextos de heterogeneidade, bem como se estabelece o diálogo entre os diversos seguimentos sociais em espaços escolares urbanos. Como afirmam Freitas \& Queiroz,

O Brasil porta uma trajetória histórica estarrecedora, um caminho percorrido de forma a desvalorizar e até mesmo a descaracterizar o indivíduo no que diz respeito à sua particularidade enquanto sociedade de cultura e língua próprias, e parte desse histórico está no desenvolvimento das práticas educacionais direcionadas às comunidades tradicionais (FREITAS \& QUEIROZ, 2012, p. 228).

Na realidade, a língua, por si só, já é um elemento de refração do significado, pois ela não é uma janela límpida, e, como consequência, a visão do mundo resultante será necessariamente parcial e enviesada. Logo, a interculturalidade deve ser, desde o início, levada em consideração, com a escolha de uma concepção pedagógica que possa promover um equilíbrio harmonioso no ensino de uma língua em detrimento de outra. Nesse sentido, "[...] a interculturalidade se constitui fenômeno inerente à humanidade, com considerável crescimento na atualidade" (FREITAS \& QUEIROZ, 2012, p. 223).

De acordo com o $\$ 2{ }^{\circ}$, do Art. 210, da Constituição Federal de 1988 “O ensino fundamental regular será ministrado em língua portuguesa, assegurada às comunidades indígenas também a utilização de 
suas línguas maternas e processos próprios de aprendizagem". (BRASIL, 2016, p. 122). Nesse sentido, é importante salientar os argumentos de Pimentel \& Borges

Nessa experiência pedagógica, os indigenas não são sujeitados a copiar o que já foi copiado, mas produzir conhecimento que lhes permite continuar aprendendo e se atualizando a vida toda. Uma coisa é absorver conteúdos. Outra, bem diferente, é reconstruí-los, investindo neste processo novidades epistêmicas (SILVA \& BORGES, 2015, p. 06).

Assim, a experiência com professores de língua portuguesa construída nas interações promovidas no dia a dia da sala de aula tem apontado algumas questões históricas, culturais e sociointeracionais que envolvem os desafios enfrentados pelos profissionais da linguagem no que diz respeito ao processo de ensino da segunda língua para alunos indígenas da Etnia Xavante em escolas públicas estaduais urbanas.

De acordo com Freitas \& Queiroz é preciso refletir sobre "[...] a distância cultural entre os povos, e que estes estão cada vez mais presentes um na sociedade do outro, é natural que se pense no impacto e/ou divergências existentes no ambiente de convívio entre as diferentes culturas". (FREITAS \& QUEIROZ, 2012, p. 224). Seguindo a linha de pensamento das autoras, o que se pôde notar é que o conflito resultante do encontro dos diferentes costumes estabelece-se não só na aprendizagem da Língua Portuguesa, mas, sobretudo, em suas produções textuais.

Dessa forma, propor-se alguns caminhos na busca do aprimoramento dessas habilidades, tendo como recurso as práticas interculturais, voltadas para o ensino da segunda língua como forma de garantir aos docentes não indígenas mais reflexões, questionamentos, significados e conceitos de línguas que pertencem a diferentes tipologias. Para tanto, há de se levar em conta que o cenário da sala de aula, no ensinar e aprender uma língua, é marcado por vieses sociodiscursivo, político-ideológico, culturais e linguísticos. Daí o interesse pela eficácia da construção sobre os pilares de duas coisas tão presentes nos paradigmas atuais: alunos indigenas e o ensino da Língua Portuguesa em contexto intercultural. 
Alunos indígenas da etnia xavante e professores não índios: o ensino da língua 2 em contexto de interculturalidade | 221

\section{Escola: encontro de culturas e suas implicações}

É importante não apenas considerar o papel da escola em relação aos conteúdos, mas, sobretudo e, fundamentalmente, os cenários de apresentação de como acontecem as ações educativas individuais e coletivas, considerando que a cultura e os aspectos linguísticos do outro possam ser ressignificados no encontro de diferentes visões de mundo.

Assim, as escolas públicas urbanas estaduais de Barra do Garças/MT, constituem-se em espaços em que o aluno indigena vai conviver com quem nunca fez parte dos seus significados, ou seja, vai conviver com diferentes culturas, de diferentes classes sociais e, principalmente, de diferentes usos linguísticos. Os fenômenos sociais e a migração desses alunos da aldeia para os cenários urbanos têm interferido, sobretudo, nas questões organizacionais e didáticopedagógicas das escolas.

Verifica-se, assim que, no sentido dicionarizado a palavra "escola" traz como primeira acepção: "[...] estabelecimento público ou privado no qual se ministra, sistematicamente, ensino coletivo". (HOUAISS, 2001, p. 1.206). Esse estabelecimento de ensino formado por uma coletividade pressupõe certo número de pessoas formado por professores, funcionários e, em sua maioria, alunos que permanecem em um local determinado. Dessa maneira, a escola é uma estrutura humana, conceitual, onde, supostamente, se ensina e se aprende desde os primórdios da história da educação. Nesse sentido, a escola está presente nos mais variados países e locais, inclusive em comunidades indigenas, a fim de colocar em prática as diferentes situações educacionais. Portanto, o que se preconiza como ensino coletivo nos espaços urbanos, percebidos durante a pesquisa, não passa de um ensino elitizado e preconceituoso, principalmente, quando se tratam de alunos indígenas presentes nessas escolas.

Nessa linha de raciocínio, consolida-se a crença de que é importante ensinar teorias não só as relativas aos usos linguísticos, mas, também, as que podem trazer aportes para uma prática educacional que reconhece o direito de cada um dos envolvidos nos aspectos relevantes ao ensino do funcionamento da língua portuguesa e da língua materna. Para Pimentel da Silva: "Quando os indigenas lutam pela sobrevivência de suas línguas, estão lutando também pela manutenção da sabedoria nela guardada". (PIMENTEL DA SILVA, 2010, p.14)

Para garantir uma educação intercultural de qualidade é importante que se faça a escolha de um novo tipo de formação, baseada na produção dos saberes e do conhecimento a fim de renovarem situações 
222 | Marly Augusta Lopes de Magalhães e Mônica Maria dos Santos

variadas de interação entre professores, alunos indígenas e não indigenas. Assim sendo, "[...] toda experiência de um individuo é transmitida aos demais, criando assim um interminável processo de acumulação”. (LARAIA, 2009, p.52)

Espera-se, assim, que nessa transmissão de experiência os alunos indígenas possam entender a distância que a língua impõe aos falantes de diferentes culturas, tanto na maneira de informar quanto na de interagir com o seu interlocutor não indígena.

Para Bakhtin, os processos que constituem a linguagem são, portanto, 'sócio-históricos e por isso a língua não pode ser estudada fora de seu contexto, fora de suas condições de produção, já que a palavra revela-se, no momento de sua expressão, como produto da interação viva das forças sociais' (BAKHTIN, 2002, p. 66).

Sabe-se que o problema do indigena, em ambientes escolares urbanos, começou a ser apontado nos primórdios da colonização, e ainda não encontrou solução digna, que seja capaz de resolvê-lo, já que as prioridades voltadas para a educação intercultural, em vez de criar espaços para um ensino alçado às condições sociointeracionais e culturais desses alunos, não seguem as políticas públicas de inclusão e, desta forma, geram maus frutos nas relações educacionais e sociais. Nos dizeres de Neves, "Não há dúvida de que é papel da escola prover para seus alunos a formação necessária para que eles sejam usuários da língua no padrão necessário à ocupação de posições minimamente situadas na escala social”. (NEVES, 2002, p. 231)

Assim, o processo intercultural deve ser levado em consideração, pois há de se acrescentar que o ensino, nessa perspectiva, não é apenas traço de encontro e confronto entre as etnias, mas, sobretudo, uma proposta para que se promovam as relações sociais a partir da articulação entre os diferentes modos de representação do mundo.

O desafio que se coloca é a ampliação da competência não só linguística, mas também comunicativa dos alunos indígenas, a fim de que possam investigar o modo como o sentido da interlocução é construído, e o que ele significa para cada comunidade linguística.

Pode-se dizer, ainda, que o maior desafio dos professores não indigenas é o de ensinar aos alunos indígenas transitando no espaço da diversidade linguística, cultural, costumes, cores, palco em que os autores convivem diariamente. Outro fator relevante no ensino da língua 2 para 
Alunos indígenas da etnia xavante e professores não índios:

o ensino da língua 2 em contexto de interculturalidade | 223

os alunos indigenas da Etnia Xavante é a dificuldade de comunicação proveniente dos variados níveis do português falado, o que interfere nas diferentes interpretações de mundo e seus significados.

A profunda diferença para com as outras culturas era uma garantia de que elas podiam existir a sua própria maneira $\mathrm{e}$ segundo os seus próprios termos. [...] Agora, quando é claro que essa situação já não prevalece quando todos cada vez mais apertados num pequeno planeta, estão profundamente interessados em todos os demais e nos assuntos que lhes dizem respeito assuma a possibilidade de perda dessa integridade em função da perda dessa indiferença (GEERTZ, 2001, p. 72).

Cabe considerar que, as exigências que se concretizam na demanda da liberdade de comunicação e do diálogo só podem ser satisfeitas em cada situação que determina as escolhas culturais, sociais, psicológicas e textuais que perpassam todos os níveis da linguagem. Ela garante um papel preponderante na construção do sujeito social. Por meio da linguagem verbal (falada ou escrita) e não verbal é possível criar e destruir com igual força. É possível unir e separar vidas, é possível descrever as diversas epopeias ou racionalmente a natureza e suas façanhas.

\section{Distanciamento da prática e da realidade}

A busca por um diálogo bem sucedido revela, como consequência, outra necessidade que é a da interação entre os falantes da língua. $O$ diálogo, para se tornar pleno, necessita estar em contato com outros diálogos, pois só assim é possivel dar sentido ao processo comunicativo.

Todo ato comunicativo tem como propósito gerar sentidos, a partir dos diversos códigos e meios, nos mais variados contextos. Para Neves: "Já se demonstrou à sociedade que ações episódicas não funcionam, e, pelo contrário, podem desestabilizar os processos, quer por estímulo criado por uma consciência de impotência, quer pela própria confusão que conceitos mal digeridos podem provocar". (NEVES, 2002, p. 232)

Por conhecer o alcance e o peso provocados pelos argumentos de Neves, bem como as interferências que ocorrem em todos os processos sociointeracionais é que se elaborou o curso de formação com a 


\section{4 | Marly Augusta Lopes de Magalhães e Mônica Maria dos Santos}

finalidade de refletir sobre as práticas interculturais em ambientes de sala de aula e, ao mesmo tempo, estudar a possibilidade de abertura de novos caminhos que assegurassem o conhecimento, dos professores não índios, sobre a cultura e a língua Xavante na perspectiva do ensino e, assim, facilitar a interação e o diálogo, elementos essenciais para a melhoria de vida de seus integrantes.

O curso teve como referência a base de conhecimento dos professores não indigenas sobre o ensino, em contexto intercultural considerando que a prática e os saberes do professor não podem ser separados dos usos e funcionamento da língua, mas que se entrelaçam numa situação de trabalho.

O intuito foi, com o curso de formação de professores, verificar os conflitos e os elementos limitadores existentes na interação de sala de aula, entre alunos indígenas/não indigenas e professores não índios. Como afirma Neves, "[...] o homem fala da linguagem porque reflete, e reflete sobre suas próprias faculdades e atividades, sobre os seus dons e seu desempenho". (NEVES, 2002, p. 18)

Assim, desencadeou-se, inicialmente, uma discussão com os professores da rede pública de ensino a fim de compreender o que tinham em mente com relação aos temas interculturalidade, interdisciplinaridade, inclusão, ensino bilingue, entre outros.

No âmbito dessas decisões, considerou-se a importância da relação entre as diferentes culturas, a articulação de indigenas e não indigenas, a maneira de informar de cada um e, ao mesmo tempo, divulgar os saberes e valores de cada grupo social presente. Diante dos resultados da ação, planejar as situações a serem trabalhadas visando respeitar o direito de cada comunidade presente, tornou-se uma necessidade tendo em vista a participação ativa de todos. De acordo com o Referencial Curricular Nacional para as Escolas Indigenas (RCNEI)

[...] a educação escolar indígena deve se fundamentar na educação e nos conhecimentos tradicionais desses povos, o que implica sua forma de transmissão de conhecimentos, sua percepção do mundo e do homem, o que, por sua vez, envolve a maneira como se organizam socialmente, culturalmente, economicamente, politicamente, e religiosamente enquanto sociedade (BRASIL, 1998, p. 22).

O que se percebeu nesse encontro cultural entre os profissionais da educação é que há um abismo entre a visão de inclusão e aceitação por 
Alunos indígenas da etnia xavante e professores não índios: o ensino da língua 2 em contexto de interculturalidade | 225 parte dos professores não indigenas, seus pensamentos são caracterizados pela fragmentação e pelo distanciamento, enquanto, para os professores indígenas seus pensamentos são mais holísticos e de aproximação.

Assim, o esforço para a promoção de interação fez com que o caminho pretendido tomasse outra direção, pois os dados coletados in loco apontaram que dos setenta e quatro (74) professores inscritos, cinquenta e oito (58) responderam que não estavam preparados para os novos enfrentamentos da sala de aula, ou seja, não estavam preparados para trabalhar com a diversidade, onze (11) admitiram que estavam preparados para tratar dos confrontos existentes em sala de aula, entre culturas e línguas tão diferentes e, apenas cinco (5) não se posicionaram.

Percebeu-se, portanto, que não apenas os professores não indigenas que atuam no ensino da Língua Portuguesa precisam de informações referentes a interculturalidade, bilinguismo e a interdisciplinaridade, mas todo o coletivo escolar.

Bakhtin considerou que "[...] o homem, fora das condições socioeconômicas objetivas, fora de uma sociedade, não tem nenhuma existência. Só como membro de um grupo social, de uma classe, é que o indivíduo ascende a uma realidade histórica e a uma produtividade cultural”. (BAKHTIN Apud FREITAS, 1994, p.126)

\section{Análises dos dados}

Todo trabalho, a partir do conteúdo analisado, necessita de que seus dados sejam refletidos e socializados nas diversas formas de compreender, de explicar e interpretar a relevância das informações apreendidas na troca de experiências com os sujeitos da pesquisa. E, assim, suscitar novas discussões, novos métodos que possam redefinir a situação vivenciada.

Assim, o que se percebeu nas respostas dos professores não indigenas aos questionamentos iniciais foram suficientes na definição do perfil de cada um sobre a presença dos alunos indígenas da Etnia Xavante em escolas públicas urbanas. A maioria dos docentes, cinquenta e oito (58), sente-se despreparada para trabalhar com a diversidade e para enfrentar a nova realidade das escolas públicas urbanas diante dos conceitos que emergem nas diferentes áreas do saber, ou seja, os professores não indigenas ainda seguem a política do autoritarismo destruidor da cultura do outro, do silenciamento das vozes e apagamento da língua materna. Nessa linha, os estudos de Ferrarezi têm mostrado que: 
Quando falamos em silêncio na escola, pensamos apenas no fato de que mandamos as crianças ficarem quietas nas aulas. Essa é uma forma ingênua de ver o silêncio nas escolas brasileiras. Na verdade, há um processo muito mais complexo de silenciamento, de submissão, de controle, que silencia a mente, as ações, e, finalmente a voz (FERRAREZI, 2014, p. 23).

Assim, a análise da resposta dos onze (11) docentes, que disseram sim, apoia-se nos argumentos de Yinger:

Sobre a discriminação, há também o trato "igual" dado aqueles que são "desiguais" [...], uma escola que recebe uma clientela variada, e nivela todos os alunos pelo nível dos que têm uma condição socioeconômica melhor, ignorando aqueles que são carentes e considerando todos iguais, são atitudes que acabam engendrando discriminação e preconceito (YINGER AL, 1998, s/p.).

Merece destaque, ainda, a omissão de cinco (5) professores. Um olhar mais atento mostra que esses professores consolidam e fortalecem a desigualdade, a submissão dos alunos indígenas, apoiados em um discurso de supervalorização da língua oficial de ensino (portuguesa), bem como de seus aspectos culturais. Configurando-se, assim, a mesma intencionalidade opressora demonstrada, por outros professores, no decorrer dos encontros.

Todavia, as posturas adotadas foram entendidas e interpretadas como processos mentais preconceituosos que subjazem, desde épocas distantes e que se revigoram diante de outros povos e de outras culturas no exercício da cidadania.

Notou-se que o discurso dos docentes está totalmente desvinculado de suas práticas de ensino, uma vez que não estão empenhados, de maneira satisfatória, com a educação dos alunos indigenas.

$\mathrm{O}$ que se percebeu durante os encontros: os professores não indigenas ainda conservam as marcas de superioridade de seus conhecimentos, de sua cultura e de sua língua. E com isso esmaga a criatividade, o conhecimento e silenciam as vozes dos alunos indigenas em contextos das escolas públicas urbanas. Para Ferrarezi, “[...] a prática 
Alunos indígenas da etnia xavante e professores não índios: o ensino da língua 2 em contexto de interculturalidade | 227

do silenciamento é tão antiga nas escolas brasileiras que já temos gerações silenciadas formando gerações para o silêncio”. (FERRAREZI, 2014, p. 78)

\section{Elementos limitadores do ensino da língua 2 para alunos indígenas da etnia xavante}

$O$ que se pôde verificar é que existem alguns elementos que limitam o ensino da língua portuguesa para alunos indígenas da Etnia Xavante matriculados em escolas públicas urbanas, entre os quais: a língua, no seu aspecto oral e escrito. $O$ distanciamento entre a língua oficial de ensino e a língua materna dos alunos indigenas. Independente da identidade ética e cultural, o ensino da língua é comum para todos os alunos participantes do mesmo ambiente escolar. Como se todos os presentes dominassem a mesma lingua.

Dessa forma, pode-se afirmar que grande parte das dificuldades enfrentadas pelos alunos, dessa etnia com relação ao domínio de uma competência do idioma português, está diretamente relacionada com o domínio do sistema fonológico dessa língua, dificuldade que aumenta, sobretudo, porque o sistema fonológico do Xavante não possui alguns fonemas existentes na Lingua Portuguesa.

O sistema fonológico do português tem 33 fonemas,

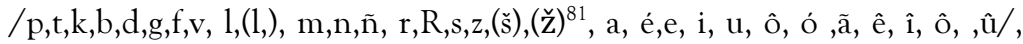
$(\mathrm{y}, \mathrm{w})$ representados por um alfabeto de 26 grafemas, ( a,b,c,d,e,f,g,h,i,j,l,m,n,o,p,q,r,s,t,u,v,x,z.), enquanto que o sistema de escrita do Xavante, introduzido a partir dos anos 1970, é representado por 20 fonemas /a,b,d,e,h,i,m,n,o,p,r,(s),t,u,w,y,(z),(ts),(dz)/ e 17 grafemas: a,b,d,dz,e,h,i,m,n,o,p,r,t, ts,u,w,y. Acrescidos do apóstrofe ( ' ), que em português é uma notação léxica e na língua indígena Xavante representa um fonema consonantal glotal, exemplo: dato'ba "pessoa cega". Os fonemas, com suas respectivas letras, que são comuns na língua portuguesa e na lingua Xavante, segundo (LACHNITT, 1999, p.14),

\footnotetext{
${ }^{81}$ Os símbolos utilizados seguem em geral o IPA, todavia, por limitações de fontes, foram adotados simbolos especiais para representar os seguintes sons:

- consoante lateral (como em palha): [1,];

- consoante fricativa palatal surda (como em chá): [š];

- consoante fricativa palatal sonora (como em já): [ž]

- a vogal anterior média aberta (como em café): [é]

- a vogal posterior média aberta arredondada (como em pó): [ó].
} 
228 | Marly Augusta Lopes de Magalhães e Mônica Maria dos Santos

$(/ \mathrm{a} / \underline{\mathrm{a}}, / \mathrm{b} / \underline{\mathrm{b}}, / \mathrm{d} / \underline{\mathrm{d}}, / \mathrm{e} / \underline{\mathrm{e}}, / \mathrm{e} / \underline{\mathrm{e}}, / \mathrm{i} / \underline{\mathrm{i}}, / \mathrm{m} / \mathrm{m}, / \mathrm{n} / \underline{\mathrm{n}}, / \tilde{\mathrm{n}} / \underline{\tilde{n}}, / \dot{\mathrm{o}} / \underline{\mathrm{e}}, / \mathrm{o} / \underline{\mathrm{o}}$, $/ \mathrm{p} / \mathrm{p}, / \mathrm{r} / \mathrm{r}, / \mathrm{t} / \mathrm{t}, / \mathrm{u} / \underline{\mathrm{u}})$.

Na língua escrita Xavante $\underline{z}$ e $\underline{s}$ são letras que apenas aparecem combinadas com $\underline{\mathbf{t}}(\mathrm{ts})$ e $\underline{\mathbf{d}}(\mathrm{d} z)$, enquanto que na língua portuguesa essas mesmas letras representam fonemas diferentes. Em português existe a combinação gráfica $\underline{\mathrm{d} z}$ para diferenciar os fonemas /d/ oclusiva simples surda dental de /dz/ oclusiva simples sonora palatal, em seu aspecto fonético. Essa última ocorre como variante do fonema /d/ quando

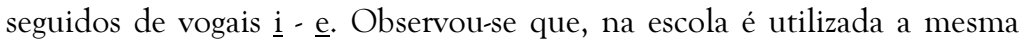
forma para representar duas línguas com notáveis diferenças fonológicas, sem nenhum parentesco linguístico.

Os contrastes assinalados na expressão oral e escrita de ambas as línguas costumam provocar distorções na pronúncia e na escrita em português. Os alunos indigenas que passam pela experiência de alfabetização usam, muitas vezes, de maneira diferente os grafemas e as notações léxicas e têm, ao mesmo tempo, muitas dificuldades tanto na produção como na compreensão textual exigida pela escola. Como se verifica nos textos produzidos por alunos indígenas que cursam o ensino médio:

[...] o mundo do brasileiro da Educação, guese (quer) melhora, na Faculdade e Escola Pública. A educação tem valorizo(valor) para o mundo... paro (para) a sociedade. (texto produzido em 12/09/2015)

[...] essa terra antes pouco ocupado e cobertas de vegetação, começam e sem (ser) povoadas, a receber asfalto canalização de água casas e edifícios que substituem a antiga paisagem. (texto produzido em 12/09/2015)

Estudos de Emília Ferreiro apontam que "[...] para alcançar uma escrita não bastaria apenas possuir uma linguagem, seria preciso, além disso, certo grau de reflexão sobre a linguagem, que permitisse tomar consciência de suas propriedades fundamentais" (FERRIERO, 1991, p. 280).

\section{Considerações finais}

O caminho percorrido demonstrou que, mesmo depois de várias transformações ocorridas em todas as esferas econômicas, sociais e tecnológicas, não houve mudanças de paradigmas por parte de muitos 
Alunos indígenas da etnia xavante e professores não índios: o ensino da língua 2 em contexto de interculturalidade | 229 professores, em relação às formas pensar a educação intercultural. Portanto, é necessário rever e analisar criticamente o que está acontecendo com os processos pedagógicos nas instituições de ensino e, ao mesmo tempo, buscar caminhos para o seu contínuo aprimoramento.

Para reverter essa situação, antes de qualquer coisa, é primordial que se construa uma política de convivência, com vistas a criar e recriar novas práticas educativas, voltadas para o respeito e a aceitação do diferente, respeitando a cultura, a língua do outro sem discriminação e, ao mesmo tempo, combater a prática de nivelamento entre culturas e línguas tão diferentes. Nessa perspectiva, a educação escolar estaria cumprindo uma de suas principais atribuições que tem sido desenvolver um ensino que "[...] tem a tarefa de desenvolver o pensamento do aluno, a sua capacidade de analisar e generalizar para compreender os diferentes fenômenos da realidade" (MARZARI, 2016, p. 221).

Isso requer uma formação pautada em referenciais que discutem práticas inclusivas e interculturais que ainda estão distantes da formação dos profissionais que atuam nas instituições de ensino observadas.

Assim, depois de vários meses de observações e reflexões, chegouse à conclusão de que para assegurar a qualidade do ensino intercultural é necessário que se promovam vários debates nas universidades, nas escolas públicas e particulares, nos centros de formação de professores, nas comunidades indígenas, espaços sociais importantes para a garantia de seriedade nas ações individuais e coletivas e no saber ouvir as críticas e sugestões, respeitando as diferentes opiniões.

E por último, propor novos encontros a fim de se enfatizar que essa não é uma ação individual e imediata, mas uma proposta de longo prazo que precisa envolver todos aqueles que, de alguma forma, preocupam-se com os novos desafios educacionais, mais especificamente das minorias.

\section{REFERÊNCIAS}

BAKHTIN, M. Problemas da Poética de Dostoiévski. 3. ed. Traduzido por Paulo Bezerra. Rio de Janeiro: Forense Universitária, 2002.

BRASIL. Constituição Federal de 1988. Promulgada em 5 de outubro de 1988.

em: 
230 | Marly Augusta Lopes de Magalhães e Mônica Maria dos Santos

<http://www.planalto.gov.br/ccivil_03/constituicao/ConstituicaoCompi lado.htm>. Acesso em: 02 jan. 2016.

BRAZIL. Referencial Curricular Nacional para Escolas Indigenas. /Ministério da Educação e do Desporto, Secretaria de Educação Fundamental. Brasília: MEC/SEF, 1998.

FERRAREZI, Celso Júnior. Pedagogia do silenciamento: a escola brasileira e o ensino de língua materna. São Paulo: Parábola, 2014.

HOUASSIS, Antônio. VILLAR, Mauro de Salles. Dicionário Houassis da Lingua Portuguesa. Rio de Janeiro. Objetiva, 2001.

FERREIRO, Emilía. et. TEBEROSKY, Ana. Psicogênese da língua escrita. Porto Alegre: Artes Médicas, 1985.

FREITAS, Maria Teresa de Assunção. Vygotsky e Bakhtin Psicologia e Educação: um intertexto. São Paulo, 1994.

FREITAS \& QUEIROZ. O eu e o outro: o processo de ensino aprendizagem no contexto intercultural. Revista de Antropologia - ano 4 volume 5, 2012.

GEERTZ, C. A interpretração das culturas. Rio de Janeiro. LTC, 1989.

LACHNITT, G. Damreme'uwaimramidzé - Estudos sistemáticos e Comparativos de Gramática Xavante, Campo Grande, Missão Salesiana de Mato Grosso, 1988.

LARAIA, R. de B. Cultura: um conceito antropológico. Rio de Janeiro. Jorge Zahar Ed. 2009.

MAGALHÃES, E D. Legislação Indigenista Brasileira e Normas Correlatas. 2. ed. Brasília: FUNAI/CGDOC, 2003.

MARZARI, Marilene. Ensino e Aprendizagem de Didática no curso de Pedagogia: contribuições da teoria desenvolvimental de V.V. Davydov. Jundiaí. Paco Editorial, 2016. 
Alunos indígenas da etnia xavante e professores não índios: o ensino da língua 2 em contexto de interculturalidade | 231

MINAYO, M. C. Pesquisa Social: teoria, método e criatividade. Petrópolis, Vozes, 2002.

NEVES, Maria Helena de Moura. Ensino de lingua e vivência de linguagem: temas em confronto. São Paulo: Contexto, 2010.

Texto e gramática. São Paulo: Contexto, 2006.

A gramática: história, teoria e análise, ensino. São Paulo: Editora UNESP, 2002.

PIMENTEL DA SILVA, M. S.; BORGES, M. V. (Org.). Cidadania, interculturalidade e formação de docentes indigenas. Goiânia: UCG, 2010. v. 1. 170

PIMENTEL DA SILVA, M. S; ROCHA, Leandro M. Educação bilíngue intercultural entre povos indígenas brasileiros. Extensão e Cultura (UFG), v. n 2, p. 7-182, 2006.

REGO, Teresa Cristina. Vygotsky: uma perspectiva histórico-cultural da educação. Petrópolis, RJ. Vozes, 2013.

SANTOS, B. A gramática do tempo: para uma nova cultura política. São Paulo: Cortez, 2006.

SILVA, Aracy Lopes de. GRUPIONI, Luís Donisete Benzi (org.) A Temática Indigena na escola: novos subsídios para professores de $1^{\circ}$ e $2^{\circ}$ graus. 2 ed. São Paulo: Global Editorial, 1998.

TOZONI-REIS, Marília Freitas de Campos. Metodologia da Pesquisa. 2 ed. Curitiba. IESDE Brasil A.S.. 2009.

YINGER, 1. Milton - Discriminación Social. in Silis, David L. (Diretor) Enciclopédia Internacional de las Ciências Sociales Vol. 8, Aguilar Ediciones, Madrid, 1976.

Recebido em: 30/06/2016

Aceito em: 15/08/2016 
232 | Marly Augusta Lopes de Magalhães e Mônica Maria dos Santos 